PANCREAS

\title{
Tumour suppression induced by the macrophage activating lipopeptide MALP-2 in an ultrasound guided pancreatic carcinoma mouse model
}

\author{
C Schneider, T Schmidt, C Ziske, K Tiemann, K-M Lee, V Uhlinsky, P Behrens, T Sauerbruch, \\ I G H Schmidt-Wolf, P F Mühlradt, J Schmidt, A Märten
}

Gut 2004;53:355-361. doi: 10.1136/gut.2003.026005

Background and aim: Carcinoma of the exocrine pancreas has a particularly poor prognosis. Therefore, novel therapeutic strategies such as immunotherapy are required. Here we investigated the immunomodulatory capacity of macrophage activating lipopeptide 2 (MALP-2), which binds to toll-like receptors 2 and 6 and induces activation of nuclear factor $\mathrm{KB}$ in monocytes. This causes the release of early stage leucocyte attracting chemokines and proinflammatory cytokines.

Methods: MALP-2 was tested in a new orthotopic ultrasound guided pancreatic cancer mouse model. This model is close to the biological situation and avoids the stress and immunostimulation caused by laparotomy. Cells from the syngeneic, highly aggressive, and metastatic cell line Panc 02 were administered orthotopically, by ultrasound guidance, to C57bl/6 mice. MALP-2 was administered intratumorally or intraperitoneally and tumour growth, immune status, and leucocyte infiltration at the tumour site were determined.

See end of article for authors' affiliations

Correspondence to:

Dr A Märten, Im

Neuenheimer Feld 350

Heidelberg, Germany;

angela.maerten@

med.uni-heidelberg,de

Accepted for publication 30 September 2003
Results: We showed a tumour suppressive effect induced by a single injection of MALP-2. Median survival increased from 21 to 30 days ( $p<0.002$ ). Combining chemotherapy (gemcitabine) with MALP-2 treatment caused further prolonged survival (median survival 27 days with chemotherapy alone $v 37$ days for combined treatment; $p<0.0002$ ). The life prolonging effect was paralleled by a significant increase in cytotoxic $T$ cells, restoration of $\beta 2$ integrin expression on lymphocytes, and high expression of CD45RB on T helper cells. Immunohistochemical stains showed strong cytotoxic T lymphocyte and natural killer cell infiltration.

Conclusions: In conclusion, in a model of orthotopic pancreatic cancer in mice, we induced a tumour suppressive effect by treatment with a synthetic lipopeptide. Treatment with MALP-2 could be an option for immunotherapy in pancreatic cancer. capable of eliminating established pancreatic tumours as long as they were small. ${ }^{3}$ These authors were further able to

Abbreviations: MALP-2, macrophage activating lipopeptide 2; NK natural killer; iNOS, inducible nitric oxide synthase; TLR, toll-like receptor; IL, interleukin; TNF- $\alpha$, tumour necrosis factor $\alpha$; PBS, phosphate

show safety and antitumour immunity using this approach in a phase I trial. ${ }^{4}$

Some immunomodulators show adjuvant activity by inducing cytokine secretion from monocytes or macrophages (for example, interferon $\alpha$, interleukin (IL)-12, and tumour necrosis factor $\alpha(\mathrm{TNF}-\alpha)$ ). Adjuvants can be the danger signals which are necessary to stimulate dendritic cells. Dendritic cells, if appropriately induced, ultimately lead to Thl dominance resulting in specific cell mediated immunity.

Such approaches may be especially helpful when tumour masses are still low or in combination with other strategies. Thus Weisenthal et al showed that adjuvant supported tumour kill was dramatically more effective when applied to tumours obtained from patients who had undergone previous chemotherapy. The authors speculated that response to chemotherapy produces massive release and processing of tumour antigens, and that this response leads to a state in which the immune system is primed (via in situ vaccination) to respond to exogenous macrophage activation signals with potent specific antitumour effects. ${ }^{5}$

buffered saline 
One plausible candidate for successful application as a strong immunomodulating substance in this context is the macrophage activating lipopeptide of $2 \mathrm{kDa}$ molecular weight (MALP-2). ${ }^{6}$ MALP-2 is a synthetic lipopeptide with two long chain fatty acid ester residues which signals through toll-like receptors 2 (TLR-2) and 6 (TLR-6), ${ }^{78}$ activates nuclear transcription factor $\kappa \mathrm{B},{ }^{9}$ induces the synthesis of a number of cytokines and chemokines, depending on its target cell, ${ }^{10}$ and also induces maturation of dendritic cells. ${ }^{11}$ Moreover, MALP-2, formerly called MDHM, induces in vitro tumoricidal activity of macrophages. It is also highly active in vivo as it induces leucocyte infiltration after intraperitoneal administration in mice or after intratracheal administration in rats. ${ }^{12}$ In this system it reduces formation of metastases in the lung. ${ }^{13}$ MALP-2 was shown to exhibit adjuvant properties when applied intranasally. ${ }^{14}$ Studies in BALB/c mice bearing methyl cholanthrene induced fibrosarcoma showed strong haemorrhagic necrosis with complete healing 10 days after MALP-2 application. ${ }^{15}$

In this study, the adjuvant and tumour suppressive capacity of MALP-2 was investigated in a syngeneic pancreatic cancer mouse model.

\section{MATERIALS AND METHODS \\ MALP-2}

MALP-2 was synthesised as described previously ${ }^{6}$ and kept as a stock solution of $1 \mathrm{mg} / \mathrm{ml}$ in water-2 propanol $(1: 1)$ at $4^{\circ} \mathrm{C}$. The exact peptide content was determined by amino acid analysis. Stock solutions were first diluted with $25 \mathrm{mM}$ octyl glucoside in saline to provide a carrier and optimal solubilisation, and were then further diluted in several steps with culture medium. The biological activity of MALP-2 was tested by nitric oxide release, as described elsewhere ${ }^{16}$ : $1 \mathrm{U}$ of activity corresponds to approximately 3 pg of MALP-2.

\section{Mice and cell lines}

Panc 02 is a murine ductal pancreas adenocarcinoma cell line which was established in 1984 in female $\mathrm{C} 57 \mathrm{Bl} / 6$ mice, as described previously. After 3-methylcholantrene induction, a ductal pancreatic adenocarcinoma was isolated and subcutaneously passaged in the syngeneic host. ${ }^{17}$ Panc 02 cells are positive for Ki-Ras, p53, Her2NEU, and CDK, as determined by real time polymerase chain reaction. The cells were a kind gift from V Schmitz (University of Bonn, Germany). Mycoplasma free Panc 02 cells were cultured in RPMI 1640 with $10 \%$ fetal calf serum and incubated at $37^{\circ} \mathrm{C}$ with $5 \% \mathrm{CO}_{2}$ in a humidified atmosphere.

Male and female C57Bl/6 mice (Charles River, Sulzbach, Germany) were kept and treated in accordance with the principles laid down in the European Community's Council Directives, and approved by the local administration (reference 50.203.2-BN22). Eight week old mice were used for the experiments.

\section{Subcutaneous tumour model}

Panc 02 cells $\left(5 \times 10^{5}\right)$ in $50 \mu \mathrm{l}$ phosphate buffered saline (PBS) were administered subcutaneously in the back of eight week old $\mathrm{C} 57 \mathrm{BL} / 6$ mice. The animals received a single intraperitoneal injection of $8 \times 10^{5} \mathrm{U}$ (approximately $3 \mu \mathrm{g}$ ) of MALP-2 in saline two days before, on the same day or two days after tumour inoculation. Control mice received injections containing control vehicle without MALP-2. Each group consisted of six mice. Growth of the subcutaneous tumours was determined using a vernier calliper. Mice were sacrificed when tumours were ulcerating or exceeded $150 \mathrm{~mm}^{2}$.

\section{Orthotopic ultrasound guided tumour model}

For ultrasound imaging, a commercially available ultrasound machine was used (HDI 5000; Philips-Ultrasound, Bothell,
Washington, USA) equipped with a high frequency linear array transducer designed for intraoperative use (CL 15-7). Imaging was performed in a real time compound imaging mode (SonoCT) operating at $10 \mathrm{MHz}$, emitting at $10 \mathrm{MHz}$, and receiving at $10 \mathrm{MHz}$. In the SonoCT mode, the digital beamformer electronically steers the transducer array about nine steering angles. For artefact reduction, frames acquired at each angle were averaged online, allowing real time imaging at frame rates of up to $10 \mathrm{~Hz}$. Line density was set to high. Persistence was disabled. The dynamic range was set to $170 \mathrm{~dB}$ and compression was 4. After anaesthesia by isoflurane, animals were placed in the supine position. The abdomen was carefully shaved. Transverse horizontal imaging planes were obtained and modified to allow visualisation of the long axis of the pancreas. To achieve the greatest benefit from real time compound imaging, potential focal lesions were placed in the central region of the image to take advantage of the complete component frame overlap (see fig 1). Images were digitally stored for offline analysis as raw data files prior to scan conversion. Image analysis was performed using a calibrated software tool (HDI-Lab, Version 1.91, Philips-Ultrasound).

We injected $5 \times 10^{5}$ Panc- 02 cells in $50 \mu$ PBS orthotopically in eight week old C57BL/6 mice. Mice received a single injection of $8 \times 10^{5} \mathrm{U}$ MALP-2 intraperitoneally or near the pancreas (intratumorally) at different time points after tumour inoculation (12 mice were treated on day +2 and six mice were treated on day +9 ). Control mice were left untreated (18 animals) or received injections with vehicle control without MALP-2 (16 animals). Tumour growth was determined every second day by ultrasound in anaesthetised animals. Twelve mice were treated intraperitoneally with $2.5 \mathrm{mg} / \mathrm{kg}$ gemcitabine five times a week for two weeks starting on day 3 after tumour inoculation. Six mice additionally received $0.3 \mu \mathrm{g}$ MALP- 2 on days +7 and +14 .

Mice were sacrificed according to our local ethics considerations when two of three criteria were met: tumour larger than $6 \mathrm{~mm}$, abdominal metastasis, or ascites formation.

\section{Preparation of spleen leucocytes and flow cytometric analysis}

Spleens from sacrificed mice were collected and single cells were passaged through a $40 \mu \mathrm{m}$ nylon mesh. They were centrifuged, resuspended in $10 \mathrm{ml}$ of erythrocyte lysis buffer (8.29 g/ $\mathrm{l} \mathrm{NH}_{4} \mathrm{Cl}, 1 \mathrm{~g} / \mathrm{KHCO}_{3}, 0.0371 \mathrm{~g} / \mathrm{l}$ EDTA in Aqua dest.),

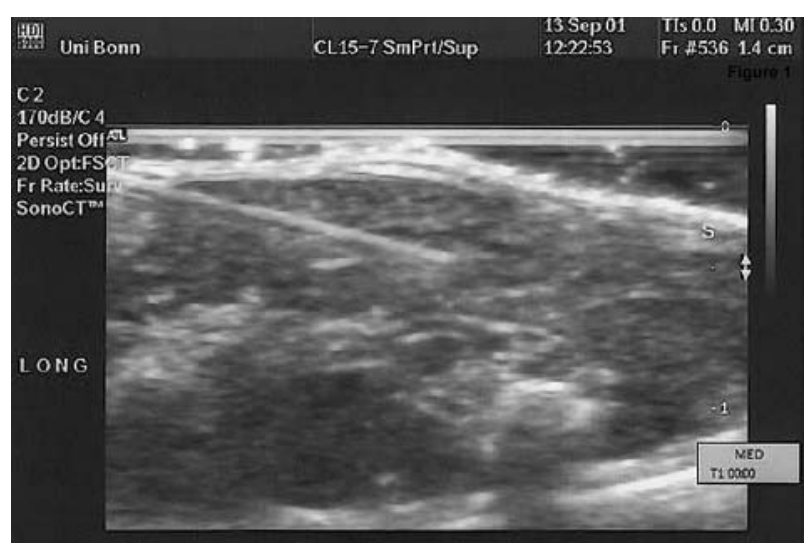

Figure 1 Ultrasound guided tumour cell inoculation. Tumour cells were inoculated into the pancreatic tail of C57BL/6 mice using SonoCT ultrasound guidance. The tip of the needle in the tail of the pancreas prior to implantation of Panc 02 cells into the pancreatic tail can be seen. The spleen was used for guidance. 
and incubated at room temperature for 15 minutes. Cells were incubated on ice for 15 minutes with the appropriate antibodies and then washed with $\mathrm{PBS} / 1 \%$ bovine serum albumin. Dual colour flow cytometric analysis was performed on a Coulter Epics XL Cytometer. Data from 30000 cells were collected and analysed. Leucocytes were phenotyped with the following monoclonal markers: CD4, CD8, CD18, CD45RB, NK1.1., and a marker for granulocytes (all from Pharmingen, Hamburg, Germany). Negative controls consisted of leucocytes labelled with rat IgG (PE/FITC). Mean fluorescence was normalised to mean fluorescence of the control antibodies.

\section{Histological staining}

Specimens were fixed immediately in $4 \%$ paraformaldehyde (for 24 hours at $4^{\circ} \mathrm{C}$ ) and then embedded in paraffin. Sections $(4 \mu \mathrm{m})$ were cut from paraffin blocks, mounted on positively charged slides (Superfrost), and air dried at $42^{\circ} \mathrm{C}$ overnight. For immunohistochemistry, fresh paraffin sections were deparaffinised in xylene, rehydrated in graded alcohols, and washed in Tris buffer. Polyclonal antimouse rabbit antibodies were used for detection of antigens (CD-4, CD-8, NCAM, and NOS2). Primary antibodies were added (dilution 1:50; all antibodies from Santa Cruz, Heidelberg, Germany) and slides incubated overnight at $4^{\circ} \mathrm{C}$. Slides were then processed on an immunostainer (TechMate 500; Dako, Hamburg, Germany).

Antibodies were detected using the ABC method (Dako) with 3-amino-9-ethylcarbazol as a visualising reagent. Sections were finally counterstained with haematoxylin, mounted in aqueous mounting media, and analysed by standard light microscopy. Replacement of the first antibody by PBS was used as a negative control to assess the specificity of the antibodies. Additionally, haematoxylin-eosin and Giemsa staining were performed.

\section{Statistical analysis}

Statistical significance of Kaplan-Meyer plots was analysed using log rank test (SPSS version 10.0 for windows). Significance of tumour growth was determined by the Mann-Whitney U test. All other parameters were tested with paired $t$ tests. Differences were considered statistically significant when $\mathrm{p}$ values were less than 0.05. Data are expressed as mean (SEM).

\section{RESULTS}

MALP-2 treatment of mice with subcutaneous tumours In order to test the capacity of MALP-2 to reduce tumour load or growth, $5 \times 10^{5}$ Panc 02 cells were administered subcutaneously. Tumours grew in all animals. Groups of eight mice received approximately $0.3 \mu \mathrm{g}$ of MALP-2 intraperitoneally on day +2 of tumour inoculation. This treatment was well tolerated. We observed significantly reduced tumour growth in mice which were treated with MALP-2 two days after tumour inoculation $(\mathrm{p}<0.03$; data not shown). These mice also showed prolonged survival compared with mice that had received vehicle control. Median survival was 23 days compared with 18-19 days in control mice.

\section{Tumour growth in the orthotopic model}

We then attempted to treat pancreatic tumours developing at their natural site. To this end we used SonoCT, a non-invasive model which has the advantage of performing real time assessment of injections (fig 1). Data were more consistent compared with measurements in the subcutaneous model (fig 2). Growth of pancreatic cancer was seen in all mice, with abdominal metastases in most cases. Liver metastasis was observed in $50 \%$ of all mice (fig $3 \mathrm{~A}, \mathrm{~B}$ ).

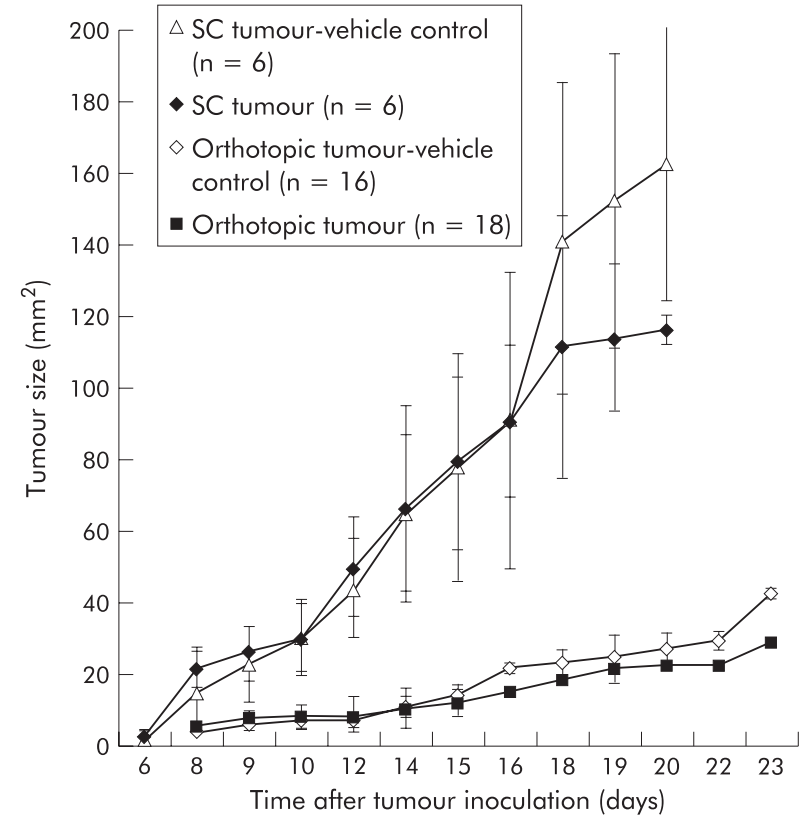

Figure 2 Growth kinetics of subcutaneous (SC) and orthotopic tumours in C57bl/6 mice. Panc 02 cells $(5 \times 105)$ in $50 \mu \mathrm{l}$ phosphate buffered saline were administered subcutaneously in the back or near the pancreas (via ultrasound guidance) of eight week old C57BL/6 mice, respectively. Tumour size was determined at three day intervals using a vernier calliper or by ultrasound, respectively. Control mice received injections containing control vehicle on day +2 . Results show data from 16-18 mice for the orthotopic model and from six mice in the subcutaneous system. Data are mean (SEM).

\section{MALP-2 treatment of mice with orthotopic tumours}

After establishment of the orthotopic model, we investigated the tumour suppressive effect of MALP-2 intraperitoneally, administered two days after tumour implantation. We found prolonged survival of MALP-2 treated mice. Median survival was 16 days in control mice versus 20 days after intraperitoneal treatment $(\mathrm{p}<0.02$, data not shown). This effect was enhanced by intratumoral injection of MALP-2. Median survival was 19 days in control mice versus 26 days after intratumoral treatment $(\mathrm{p}<0.004)$ (fig $4 \mathrm{~A})$.

Interestingly, treatment with MALP-2 nine days after tumour inoculation instead of two days produced even better results. When we treated mice with a detectable tumour burden (approximately $7.6 \quad(1.6) \mathrm{mm}^{2}$ ) with the same amount of MALP-2, median survival increased from 21 days for mice treated on day +2 to 30 days (fig $4 \mathrm{~B})(\mathrm{p}<0.002)$.

For further optimisation of the MALP-2 regimen, we treated mice once a week intratumorally with the lipopeptide. We observed no life prolonging effect compared with single administration (median survival 23 days, data not shown). There was no significant reduction in the number of metastases in MALP-2-treated animals. Most animals (27/ 29) had to be sacrificed because of tumour sizes exceeding $6 \mathrm{~mm}$ and concomitant formation of ascites.

\section{Combination of MALP-2 with gemcitabine treatment} We next examined whether MALP-2 had a beneficial effect on chemotherapy treated tumour bearing mice. Therefore, mice were treated intraperitoneally with $2.5 \mathrm{mg} / \mathrm{kg}$ gemcitabine five times a week for two weeks starting on day 3 after tumour inoculation. One group of mice also received $0.3 \mu \mathrm{g}$ MALP- 2 on days +7 and +14 .

Chemotherapy treated mice showed prolonged survival, as shown in fig 5. Median survival increased from 18 days for untreated animals to 29 days $(\mathrm{p}<0.0001)$. Mice who had also 

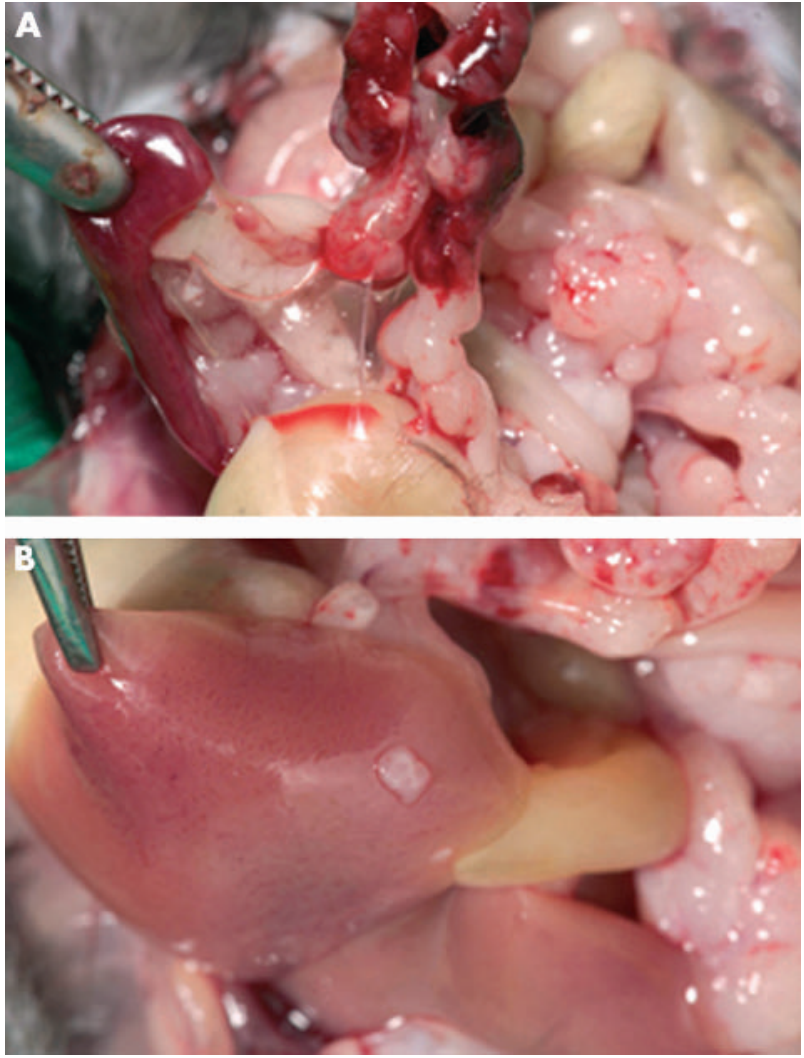

Figure 3 Growth and metastasis of orthotopically implanted Panc 02 cells. Mice were killed 21 days after orthotopic injection of Panc 02 cells. Growth of pancreatic cancer (A) was seen in all mice, with abdominal metastases in most cases. Liver metastasis (B) was observed in $50 \%$ of all mice.

received the lipopeptide survived a median of 37 days (fig 5). This increase in survival time was highly significant $(\mathrm{p}<0.0002)$ compared with the control group who received gemcitabine and vehicle control alone.

\section{Flow cytometric analysis}

In order to gain insight into the possible mechanisms that could explain the above findings, we examined leucocyte composition in the spleens of healthy, tumour bearing, treated, and untreated mice.

Generally, we observed immunosuppression in tumour bearing mice. The number of B lymphocytes was significantly lower in tumour mice $(\mathrm{p}<0.001)$ (fig $6 \mathrm{~A})$ and the $\beta 2$ integrin CD18, important for lymphocyte adhesion, was also significantly downregulated in mice with pancreatic tumours $(\mathrm{p}<0.02)$. As a marker of regulatory $\mathrm{T}$ cells, we measured $\mathrm{CD} 4^{+} \mathrm{CD} 45 \mathrm{RB}^{\text {low }}$ cells in both groups. Mean expression of CD45RB on Thelper cells was found to be strongly reduced in tumour mice $(\mathrm{p}<0.002)$. Furthermore, there was a trend towards reduction of $\mathrm{NK}$ cells, $\mathrm{CD}^{+}$cells, and $\mathrm{CD} 8^{+}$cells in tumour bearing mice but this was not statistically significant and we could not rule out the possibility that we had some contamination with other cell types (for example, litural cells) in our spleen preparations.

Flow cytometric analysis of murine spleen cells from animals treated intraperitoneally or intratumorally with MALP- 2 on day +2 or day +9 showed a significant increase in CD18 expression $(\mathrm{p}<0.024)$ (fig 6B). CD8 ${ }^{+}$lymphocytes increased significantly in all groups of MALP-2 treated mice, and particularly in the group with orthotopically implanted tumours treated on day +9 with MALP-2 $(\mathrm{p}<0.00003)$

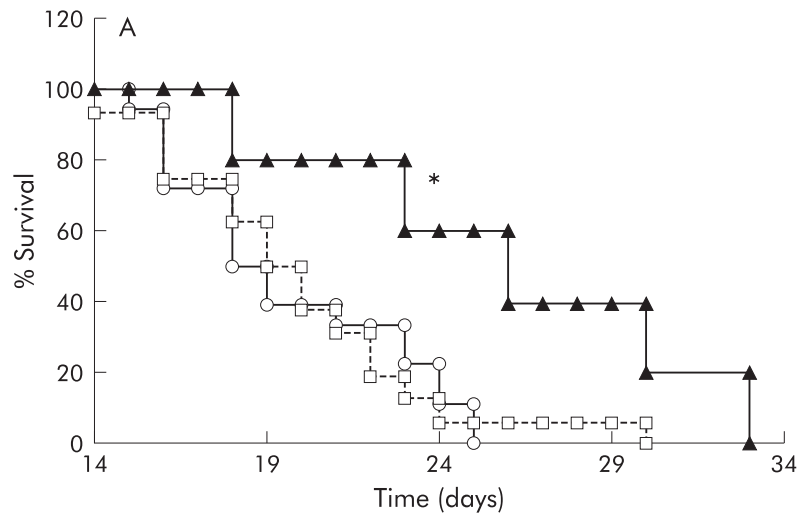

- Tumour $(n=18) \quad \square$ Vehicle control on day $+2(n=16)$ $\Delta$ MALP-2 on day $+2(n=12)$

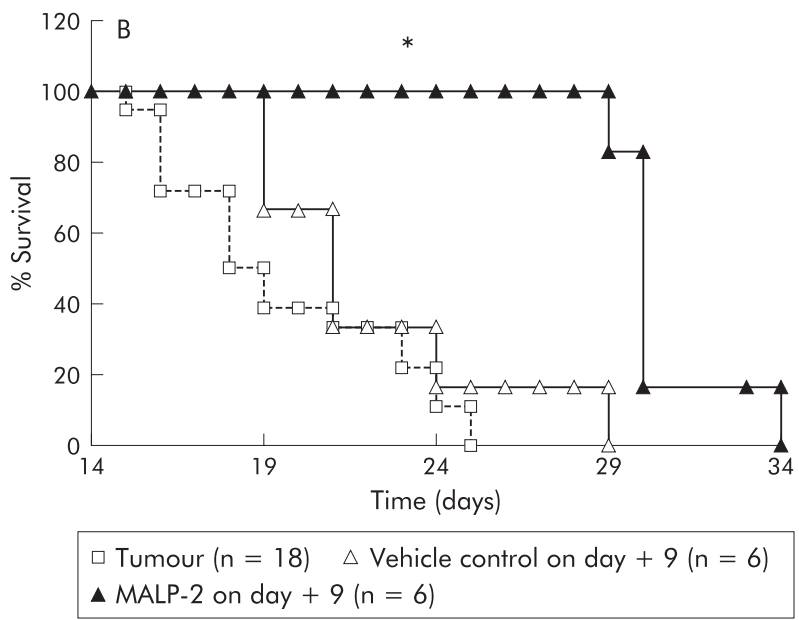

Figure 4 Macrophage activating lipopeptide 2 (MALP-2) treatment of mice with orthotopic tumours. (A) Survival curve of C57Bl/ 6 mice with orthotopic syngeneic pancreatic carcinoma. Mice were treated with $8 \times 10^{5}$ U MALP-2, or with the corresponding control, intratumorally on day +2 after tumour inoculation. Results show data from at least 12 mice. Mice were sacrificed when tumour size exceeded $6 \mathrm{~mm}$. (B) Survival curve of $\mathrm{C} 57 \mathrm{BI} / 6$ mice after MALP-2 treatment on day +9 . Mice were treated with $8 \times 10^{5} \mathrm{U}$ MALP-2, or with the corresponding control, intratumorally on day +9 after tumour inoculation. Results show data from six mice. Mice were sacrificed when tumour size exceeded $6 \mathrm{~mm}$. ${ }^{*} \mathrm{p}<0.05$.

(fig 6B). Similar results were observed regarding the number of NK cells. A significant increase in NK cells was found in mice which were treated nine days after tumour inoculation $(p<0.006)$ (fig 6B). Mean fluorescence of CD45RB on T helper cells, an indicator of Th1/Th2 balance, ${ }^{18-23}$ was significantly suppressed in tumour bearing mice and normalised or overexpressed in MALP- 2 treated mice $(\mathrm{p}<0.02$ for intraperitoneal treatment) (fig 6b). The increase in CD45RB levels on $\mathrm{T}$ helper cells in MALP-2 intratumorally treated mice (on day +2 ) compared with the control group was also significant $(p<0.0003)$. MALP-2 treatment on day +9 did not cause an increase in CD45RB mean fluorescence, a phenomenon we cannot explain.

Mice having undergone chemotherapy alone showed a similar expression profile as untreated tumour bearing mice but there was strong immunomodulation in mice treated with gemcitabine plus MALP-2. In this group, we observed a statistically significant increase in the percentage of $\mathrm{CD}_{18}{ }^{+} \mathrm{CD}^{+}$(97.6\% v 70.2\%; $\left.\mathrm{p}<0.02\right), \mathrm{CD}^{+}(12.2 \%$ v $9.3 \%$; $\mathrm{p}<0.05)$, NK $1.1^{+}(18.1 \%$ v $4.2 \% ; \mathrm{p}<0.0001)$, and CD19 $9^{+}$cells 


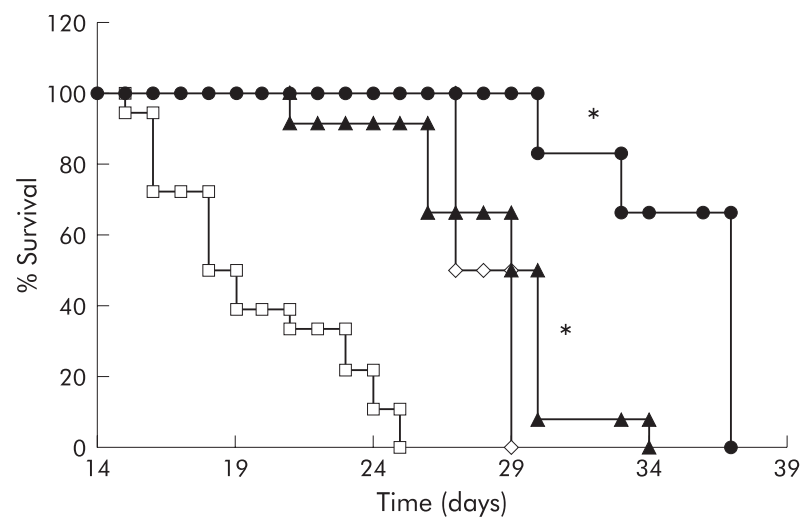

$\square$ Tumour $(n=18)$
$\Delta$ Gemcitabine alone $(n=12)$
$\diamond$ Gemcitabine + vehicle control $(n=12)$
- Gemcitabine + MALP-2 on day +7 it $(n=6)$

Figure 5 Combined treatment with gemcitabine and macrophage activating lipopeptide 2 (MALP-2) intratumorally (it). Survival curve of C57Bl/6 mice with orthotopic syngeneic pancreatic carcinoma. Mice were treated with $2.5 \mathrm{mg} / \mathrm{kg}$ gemcitabine intraperitoneally five times a week for two weeks starting on day 3 after tumour inoculation.

Additionally, one group of mice received $0.3 \mu \mathrm{g} \mathrm{MALP-2}$ on day +7 and day +14 . Results show data from at least six mice. Mice were sacrificed when tumour size exceeded $6 \mathrm{~mm}$. ${ }^{*} \mathrm{p}<0.05$.

(78.5\% $v 30.9 \% ; \mathrm{p}<0.0005)$ as well as in mean expression of CD45RB on $\mathrm{T}$ helper cells $(207.7 v 20.3 ; \mathrm{p}<0.00001)$, all compared with the respective vehicle control (data not shown).

\section{Histological staining of tumours}

In general, tumours were mostly poorly differentiated with an almost spindle cell-like morphology. In contrast with the control group, MALP-2 treated mice showed progressive, sometimes confluent, tumour cell necrosis with obvious infiltration of lymphocytes.

Lymphocytes were immunohistochemically characterised as T lymphocytes and NK cells by expression of CD4, CD8, and NCAM, respectively (fig 7A, B). The zones in the tumours with a high density of leucocytes had a correspondingly high expression of inducible nitric oxide synthase (iNOS). Infiltration of lymphocytes was more pronounced in the group treated with MALP-2 intratumorally compared with mice treated intraperitoneally.

\section{DISCUSSION}

Animal cancer models can only approximate the situation in a human cancer patient. Each model has its specific limitations and pitfalls. We used a murine in vivo model with syngeneic, highly aggressive, metastatic tumour cells carrying genetic aberrations typical of a ductal pancreatic carcinoma. We studied the effects of the immunomodulator MALP-2 alone or in combination with chemotherapy in two experimental setups. Tumour cells were either implanted into the skin or orthotopically injected into or near the pancreas. Orthotopic tumour implantation and observations were done under minimally invasive conditions, allowing us to investigate the influence of immunotherapy on tumour growth without interfering with the immune system from surgical stress or ensuing infections. Although the skin model as an experimental system is easier to handle, and treatment effects are more easily observable, the orthotopic model more closely mimics the complex situation in an affected patient. Compared with studies requiring repeated laparotomies, this
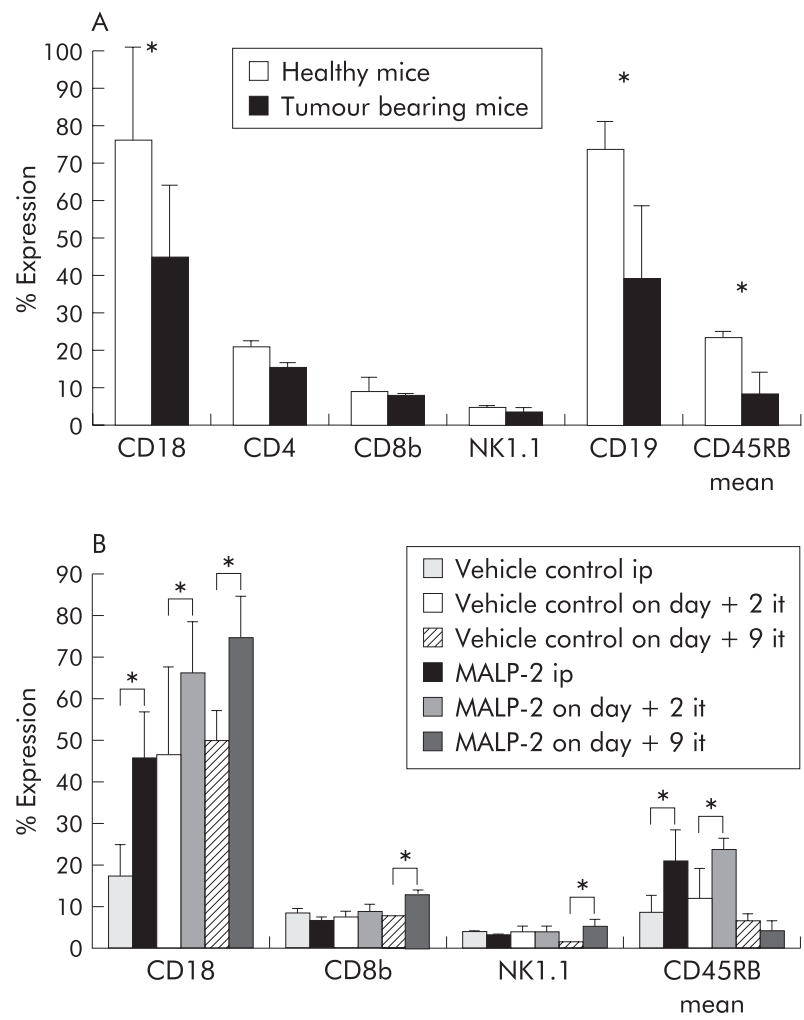

Figure 6 Flow cytometric analysis of spleen derived leucocytes. Mice with orthotopic tumours were sacrificed and the spleens were immediately removed. Leucocytes were stained with the indicated antibodies. (A) Expression of various markers in healthy and tumour bearing mice. (B) Percentage of $\beta 2$ integrin positive cells, cytotoxic $T$ lymphocytes, natural killer (NK) cells, and mean expression of CD45RB on T helper cells from tumour bearing mice after macrophage activating lipopeptide 2 (MALP-2) treatment intraperitoneal (ip) or intratumorally (it). Results show data from at least six mice. Data are mean (SEM). ${ }^{*} p<0.05$

method allows us to survey in situ tumour growth and to gather highly reproducible data compared with conservative measurement (Ziske, submitted).

MALP-2 treatment was beneficial in both experimental systems and significantly prolonged the survival time of tumour bearing mice. Combined therapy of MALP-2 with the ribonucleotide reductase inhibitor gemcitabine was particularly effective. Intraperitoneal as well as intratumoral treatment with MALP-2 were well tolerated but not equally effective. The life prolonging effect was more pronounced in the orthotopic than in the subcutaneous model, especially when animals were treated locally. Better circulation in intrapancreatic tumours and a higher initial local MALP-2 concentration may be responsible. However, even when MALP-2 was injected into the peritoneum, there were effects on the subcutaneous tumours at the back, suggesting a systemic MALP-2 effect.

MALP-2, as its acronym implies, is a lipopeptide. This class of immunomodulators signals through TLR, setting off a signal transduction cascade which results in activation of nuclear factor $\kappa \mathrm{B}$ and release of proinflammatory cytokines. Specifically for MALP-2, the formation of nitric oxide, and secretion of CXC chemokines such as IL-8 and GRO-, leucocyte attracting CC chemokines such as MIP-1, MIP-2, and MCP-1, and proinflammatory proteins such as IL-6 and TNF- by activated monocytes and macrophages have been reported. ${ }^{9}{ }^{10}{ }^{24}$ MALP-2 differs from lipopeptides derived from or analogous to those from Gram negative bacteria in that it 

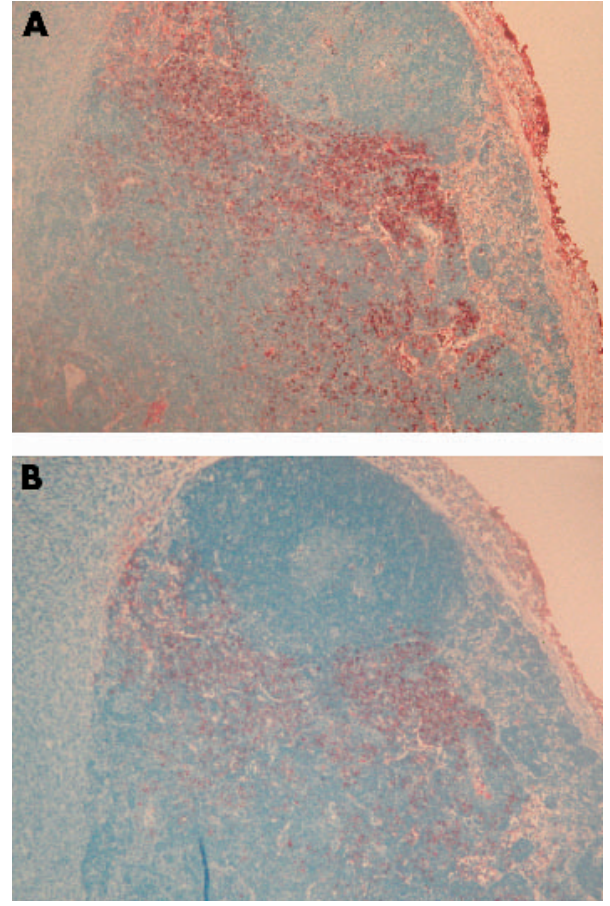

Figure 7 Immunohistochemical staining of orthotopic tumours. Histological sections from a mouse treated with macrophage activating lipopeptide 2 (MALP-2) were stained with anti-CD8 (A) and anti-NCAM (B) antibodies. Photographs were made with $100 \times$ magnitude.

carries only two fatty acid chains. ${ }^{6}$ As a consequence, MALP-2 signals through interactions between TLR-2 and TLR- ${ }^{7}$ whereas "conventional" lipopeptides and their analogues signal via TLR-2 and TLR-1. TLR-1 is expressed in all leucocytes. In contrast with TLR-1, TLR-2 is expressed in myelomonocytic elements, including dendritic cells. ${ }^{25}$ TLR-6 seems to be broadly expressed in the same manner as TLR-1 but the response to immunological agents after functional interaction with TLR-2 is different to the response that results after interaction of TLR-1 and TLR-2. ${ }^{26}$ Different receptor specificity is expected to result in different responder cell populations as expression of TLRs is subject to regulation (see for example, Underhill ${ }^{27}$ ).

Tumour suppressive effects of MALP-2 in different in vivo models were described earlier. Thus Shingu et al showed in a rat mammary adenocarcinoma model that intratracheal administration of MALP-2 reduced the number of lung metastases, ${ }^{13}$ and Galanos et al observed in Meth-A tumour bearing mice a strong haemorrhagic necrosis of subcutaneously growing fibrosarcomas after MALP-2 injection. ${ }^{15}$ This latter tumour is known to be TNF sensitive, and as TNF is induced by MALP-2, it is reasonable to ascribe the MALP-2 effect in this model primarily to circulating TNF. Fidler's group described in a series of studies the effects of synthetic lipopeptides bearing three fatty acids (CGP 31362 or JBT 3002 ) in various tumour models. ${ }^{28-34}$ The observed tumour suppressive results correlated well with high levels of iNOS in the tumour leading to autocytolyis (for example, see Xie and Fidler $^{32}$ ). We do not know whether iNOS is upregulated by MALP-2 in Panc 02 cells used in this study but believe this is rather unlikely as Panc 02 cells do not express TLR-2 which is necessary for MALP-2 signalling (Märten, unpublished data). Similarly, direct cytotoxicity of MALP-2 on tumour cells can be ruled out as no apoptotic or cytolytic effect of MALP-2 could be observed in vitro (Märten, unpublished data). However, involvement of nitric oxide generated by effector cells such as infiltrating macrophages is likely. The following observations indicate involvement of the innate as well as specific immune system.

(i) MALP-2 caused infiltration of NK cells and cytotoxic T lymphocytes 16-37 days after MALP-2 injection, and these cells were localised close to and within the tumour (fig 7).

(ii) After MALP-2 treatment, normalisation of expression of the $\beta 2$ integrin CD18 of leucocytes was observed (fig 6). Integrins are important molecules in contact dependent tumoricidal activity. Thus inhibition of macrophage mediated cytotoxicity was observed after blocking CD18. ${ }^{35}$

(iii) Similarly, an increase in expression of CD45RB was noted after MALP-2 (fig 6). High expression of CD45RB on lymphocytes seems to be associated with a Thl secretion pattern while reduced expression is associated with regulatory $\mathrm{T}$ cells and Th2 cytokines. ${ }^{18-23}$ Our data thus suggest that MALP-2 regenerates Th2 shifted nonadhesive leucocytes.

(iv) Although not demonstrated here, it was shown in cell cultures that MALP-2 causes activation and maturation of dendritic cells. ${ }^{11}$ Such dendritic cells could take up apoptotic or necrotic tumour cells and prime specific effector cells.

\section{CONCLUSION}

Immunotherapy with MALP, particularly in combination with mild chemotherapy, could be an option for treatment of pancreatic cancer after surgical intervention. Even after resection of a ductal adenocarcinoma of the exocrine pancreas patients have an especially poor prognosis, minimal residual disease being the likely source of relapse. Another possible application for MALP-2 could be in the prevention of metastasis during resection. Further studies are required for optimisation of dosage and treatment schedules.

\section{ACKNOWLEDGEMENTS}

This work was supported in part by Habilitationsstipendium of the "Lise-Meitner-Programm" of the Ministerium für Wissenschaft und Forschung (to AM), Northrhine-Westphalia, Germany.

\section{Authors' affiliations}

C Schneider, T Schmidt, C Ziske, K-M Lee, V Uhlinsky, T Sauerbruch, I G H Schmidt-Wolf, Department of Internal Medicine I, University of Bonn, 53105 Bonn, Germany

K Tiemann, Department of Internal Medicine II, University of Bonn, 53105 Bonn, Germany

P Behrens, Department of Pathology, University of Bonn, 53105 Bonn, Germany

J Schmidt, A Märten, Department of Surgery, University of Heidelberg, 69120 Heidelberg, Germany

P F Mühlradt, Wound Healing Research Group, BioTec-

Gründerzentrum, 38124 Braunschweig, Germany

\section{REFERENCES}

1 Jessup JM, Posner M, Huberman M. Influence of multimodality therapy on the management of pancreas carcinoma. Semin Surg Oncol 1993;9:27-32.

2 Bissell MJ, Radisky D. Putting tumours in context. Nature Rev Cancer 2001;1:46-54.

3 Jaffee EM, Schutte M, Gossett J, et al. Development and characterization of a cytokine-secreting pancreatic adenocarcinoma vaccine from primary tumors for use in clinical trials. Cancer J Sci Am 1998;4:194-203.

4 Jaffee EM, Hruban RH, Biedrzycki B, et al. Novel allogeneic granulocytemacrophage colony-stimulating factor-secreting tumor vaccine for pancreatic cancer: a phase I trial of safety and immune activation. J Clin Oncol 2001; 19:145-56.

5 Weisenthal LM, Dill PL, Pearson FC. Effect of prior cancer chemotherapy on human tumor-specific cytotoxicity in vitro in response to immunopotentiating biologic response modifiers. J Natl Cancer Inst 1991;83:37-42. 
6 Mühlradt PF, Kiess M, Meyer H, et al. Isolation, structure elucidation, and synthesis of a macrophage stimulatory lipopeptide from Mycoplasma fermentans acting at picomolar concentration. J Exp Med 1997;185:1951-8.

7 Morr M, Takeuchi O, Akira S, et al. Differential recognition of structural details of bacterial lipopeptides by toll-like receptors. Eur J Immunol 2002;32:3337-47.

8 Takeuchi O, Kaufmann A, Grote K, et al. Cutting edge: preferentially the Rstereoisomer of the mycoplasmal lipopeptide macrophage-activating lipopeptide-2 activates immune cells through a toll-like receptor 2- and MyD88-dependent signaling pathway. J Immunol 2000;164:554-7.

9 Sacht G, Märten A, Deiters U, et al. Activation of nuclear factor-kappaB in macrophages by mycoplasmal lipopeptides. Eur J Immunol 1998;28:4207-12.

10 Kaufmann A, Muhlradt PF, Gemsa D, et al. Induction of cytokines and chemokines in human monocytes by Mycoplasma fermentans-derived lipoprotein MALP-2. Infect Immun 1999;67:6303-8.

11 Weigt H, Mühlradt P, Emmendörfer A, et al. Synthetic derived mycoplasmal lipopeptide MALP- 2 induces maturation and function of dendritic cells. Immunobiology 2003;207:1-11.

12 Lührmann A, Deiters U, Skokowa J, et al. In vivo effects of a synthetic 2kilodalton macrophage-activating lipopeptide of Mycoplasma fermentans after pulmonary application. Infect Immun 2002;70:3785-92.

13 Shingu K, Kruschinski C, Luhrmann A, et al. Intratracheal macrophageactivating lipopeptide-2 reduces metastasis in the rat lung. Am J Respir Cell Mol Biol 2003;28:316-21

14 Rharbaoui F, Drabner B, Borsutzky S, et al. The Mycoplasma-derived lipopeptide MALP-2 is a potent mucosal adjuvant. Eur J Immunol 2002;32:2857-65.

15 Galanos C, Gumenscheimer M, Mühlradt P, et al. MALP-2, a Mycoplasma lipopeptide with classical endotoxic properties: end of an era of LPS monopoly? J Endotoxin Res 2000;6:471-6.

16 Mühlradt $\mathbf{P}$, Frisch M. Purification and partial biochemical characterization of a Mycoplasma fermentans-derived substance that activates macrophages to release nitric oxide, tumor necrosis factor, and interleukin-6. Infect Immun 1994;62:3801-7.

17 Corbett TH, Roberts BJ, Leopold WR, et al. Induction and chemotherapeutic response of two transplantable ductal adenocarcinomas of the pancreas in C57BL/6 mice. Cancer Res 1984;44:717-26.

18 Canaan A, Marcus H, Burakova T, et al. T cell control of staphylococcal enterotoxin $B$ (SEB) lethal sensitivity in mice: CD4+ CD45RB(bright)/CD4+ CD45RB (dim) balance defines susceptibility to SEB toxicity. Eur J Immunol 1999;29:1375-82

19 Alwan WH, Record FM, Openshaw PJ. Phenotypic and functional characterization of T cell lines specific for individual respiratory syncytial virus proteins. J Immunol 1993; 150:5211-18.

20 Birkeland ML, Kraus T, Tardelli L, et al. Progressive changes in CD45RB phenotype and lymphokine production by murine CD4+ T cells after alloantigen exposure. Immunology 1992;75:632-8.
21 Bass $\mathrm{H}$, Strober S. Deficits in T helper cells after total lymphoid irradiation (TLI): reduced IL-2 secretion and normal IL-2 receptor expression in the mixed leukocyte reaction (MLR). Cell Immunol 1990;126:129-42.

22 Birkeland ML, Johnson P, Trowbridge IS, et al. Changes in CD45 isoform expression accompany antigen-induced murine T-cell activation. Proc Natl Acad Sci U S A 1989;86:6734-8.

23 Bottomly K, Luqman M, Greenbaum L, et al. A monoclonal antibody to murine CD45R distinguishes CD4 T cell populations that produce different cytokines. Eur J Immunol 1989; 19:617-23.

24 Deiters U, Mühlradt PF. Mycoplasmal lipopeptide MALP-2 induces the chemoattractant proteins macrophage inflammatory protein lalpha (MIPlalpha), monocyte chemoattractant protein 1, and MIP-2 and promotes leukocyte infiltration in mice. Infect Immun 1999;67:3390-8.

25 Muzio M, Bosisio D, Polentarutti N, et al. Differential expression and regulation of toll-like receptors (TLR) in human leukocytes: selective expression of TLR3 in dendritic cells. J Immunol 2000;164:5998-6004.

26 Hajiar AM, O'Mahony DS, Ozinsky A, et al. Cutting edge: functional interactions between toll-like receptor (TLR) 2 and TLR1 or TLR6 in response to phenol-soluble modulin. J Immunol 2001;166:15-19.

27 Underhill DM. Toll-like receptors: networking for success. Eur J Immunol 2003:33:1767-75.

28 Fidler IJ, Nii A, Tsao JY, et al. Activated human blood monocytes trigger the antitumor activity of blood polymorphonuclear cells. Lymphokine Res 1989;8:427-37.

29 Utsugi T, Dinney CP, Killion JJ, et al. In situ activation of mouse macrophages and therapy of spontaneous renal cell cancer metastasis by liposomes containing the lipopeptide CGP 31362. Cancer Immunol Immunother $1991 ; 33: 375-81$.

30 Xie K, Huang S, Dong Z, et al. Direct correlation between expression of endogenous inducible nitric oxide synthase and regression of M5076 reticulum cell sarcoma hepatic metastases in mice treated with liposomes containing lipopeptide CGP 31362. Cancer Res 1995;55:3123-31.

31 Xie K, Dong Z, Fidler IJ. Activation of nitric oxide synthase gene for inhibition of cancer metastasis. J Leukoc Biol 1996;59:797-803.

32 Xie K, Fidler IJ. Therapy of cancer metastasis by activation of the inducible nitric oxide synthase. Cancer Metastasis Rev 1998;17:55-75.

33 Bruns CJ, Shinohara H, Harbison MT, et al. Therapy of human pancreatic carcinoma implants by irinotecan and the oral immunomodulator JBT 3002 is associated with enhanced expression of inducible nitric oxide synthase in tumor-infiltrating macrophages. Cancer Res 2000;60:2-7.

34 Shinohara H, Bucana CD, Killion JJ, et al. Intensified regression of colon cancer liver metastases in mice treated with irinotecan and the immunomodulator JBT 3002. J Immunother 2000;23:321-31.

35 Shrivastava A, Shishodia S, Sodhi A. Expression of LFA-1 adhesion molecules on cisplatin-treated macrophages. Biochim Biophys Acta 1998;1402:269-76. 